\title{
An Investigation on Second Language Learners' Production of Conventional Expressions in L2 Pragmatics
}

\author{
Aihemaituoheti Wujiabudula* \\ Department of English Preparatory Program, Istanbul Arel University Istanbul, Turkey \\ Corresponding Author: Aihemaituoheti Wujiabudula, E-mail: alanhoca@gmail.com
}

\section{ARTICLE INFO}

Article history

Received: April 07, 2018

Accepted: July 15, 2018

Published: October 31, 2018

Volume: 9 Issue: 5

Advance access: August 2018

Conflicts of interest: None

Funding: None

\section{Key words:}

Foreign Language Learners,

Conventional Expressions,

Pragmatic in Second Language

\begin{abstract}
This study is designed to elicit second language learners' production of conventional expressions in L2 pragmatics. A questionnaire was conducted to students who were required to write the oral responses towards 19 scenarios instead of answering the scenarios orally. In prepared scenario questionnaire, a production task was consisted of 19 scenarios, which demonstrate various speech acts. Such as, expressions of gratitude, apologies, warning, leave-taking, requests, condolences, declining offers, acceptance of offers, acceptance of request, acceptance of invitation, declining an invitation, an agreement, deflecting thanks... etc. Twenty four second grade students from Translation and interpretation department in an private university completed the questionnaires voluntarily, with no class credit and compensation available for participating in this research. No level differences were taken into consideration, and it is assumed that all participants are nonnative upper-intermediate and advanced English users. Content analysis was applied to measure the frequency and rate in production of conventional expressions.
\end{abstract}

\section{INTRODUCTION}

Formulaic language has been a hot research topic by many researchers over the past decades. Under the umbrella of formulaic language, conventional expressions has been taken into researchers' consideration and it has become a major research areas in second language acquisition. Conventional expressions in sociolinguistics plays an important role in L2 language comprehension and acquisition.

Conventional expressions includes strings of words (I am joking, I am sorry, no problem. etc.) which predominantly applied in spoken language, often used by native speakers of English users within the same speech community. Many researches has put a glance on conventional expressions and reported that there is a lack of usage of these expressions by learners in general (Roever, 2005, Scarcella, 1979, Bardovi-Harving, 2009).

From sociolinguistic perspective, it is crucial to learn routines at any learning stage since it incorporates the knowledge that any society shares and it is essential to learn that it helps improve verbal communication in daily lives. It is very difficult to say that everyone, even advanced speakers have trouble learning it seamlessly, even some learners feel uncomfortable using some conventional expressions (Bardovi-Harlig, 2012). It might be also difficult for some others to link the meaning of these expressions to their target language, which they cannot control the form.
Achieving pragmatics in speech community enables individuals to produce meaning in socially acceptable manner. Not only it is beneficial for individuals to interpret the meaning of these conventional expressions, but also it entails having ability to implicit or explicit what has stated, according to context (Taguchi, 2007).

Conventional expressions throughout the research is called lexical phrases, and it has been paid attention by English instructors and many researchers via demonstrating an extensive inventory of expressions (Nattinger and DeCarrico, 1992). To determine if learners know the meaning of conventional expressions, Kecskes carried out a research on it. The research results reveals that learners recognized literal meaning of these expressions than idiomatic meaning of these. It is also found that production of these expressions were always grammatical and appropriate, but it is not native like among Asian participants in this research (Bardovi-Harlig, 2009).

In 2005, Rover also conducted a research to test pragmatic competence of learners, which includes decoding speech acts, selection of turns for context provided a multiple choice task, and production of a turn. Rover concluded that learners who were exposed to English language environment score performs betters than those with less exposure which suggests that a great knowledge of situational expressions as measured by this task. (Rover, 2005). 
Several researches has been conducted as to production of conventional expressions. Bardovi-Harlig and Vellenga performed a research on the effect of instruction on oral conventional expression in L2 pragmatics. 36 university students attended the survey by demonstrating pre-test-instruction and post-test design. Participants were divided into 2 groups of three classes; in each group, students were given instruction on a various conventional expressions. It was found that learning conventional expression is responsive to instructions and constrained by the transparency of expressions and learners level of linguistic improvement (Bardovi-Harlig, Vellenga, 2012).

A similar study was also performed about pragmatic analysis about thanking strategies among Kurdish speakers of Ilam based on gender and age. From this research, it concluded that "Thanking", "Positive feeling ", "Appreciation "were seen as most frequent applied strategies among participants under 30 years. The common strategies among participants were found the common strategies about "Thanking", "Positive feeling" and "Appreciation". It was also found that this pragmatics listed above were the most frequent in male participants while this pragmatics were the general tendency of female participants. It was also suggested that it is beneficial for learners to acquire pragmatics to develop their pragmatic competence (Yusefi, Gowhary, Azizifar, Esmaeili, 2015).

Edmonds also carried out a study investigating pragmatics and processing on conventional expressions, which aims to address questions regarding native and non-native speaker's knowledge and processing of such expressional strings. By the participants answers, it revealed that all groups evaluated the conventional expressions similarly and significantly different from the matched conditions, which includes grammatical, but not conventional expressions (Âmânda Edmonds, 2014).

Usó-Juan et al. also studied on the conventional expressions of complaining and apologizing to assess learners' performance. Pragmatic expressions, such as conventional expressions, is found difficult by many foreign language learners since contextual factors and cultural background involved in it. In this study, authors investigate the learners choice of semantic formula applied to apologize and complain in situations, which differs according to social distance, socio-pragmatic factors and severity of offence. This study aforementioned revealed that foreign language learners are limited to make themselves clear when they apologize or complain about situation (Usó-Juan, Martínez-Flor, 2015).

\section{METHOD}

The task was completed during 40 minutes in a language laboratory by handing out the production task questionnaire which includes total 19 scenarios. In the first part of production task, 2 examples were given to clarify and make students clear about how it is supposed to be responded. All given scenarios elicit conventional expressions.

All participants took part in this study voluntarily, no course credit or compensation available for completing production task paper. All participants are from $2^{\text {nd }}$ grade undergraduate students in Translation and Interpretation
Department, no level differences is taken into account and all participants are supposed to be upper-intermediate and advanced users of English language.

Production task consists of 19 scenarios which was designed by Bardovi-Harlig (2009), which elicit conventional expressions. These scenarios elicit a variety of speech acts: expressions of gratitude, apologies, warning, leave-taking, requests, condolences, declining offers, acceptances of offers, acceptance of request, acceptance of an invitation, an invitation, declining an invitation, an agreement, deflecting thanks and an introduction.

An example of production task scenarios is provided here.

Example:

Scenario: You're talking outside with your longtime neighbor and he tells you about his dog's accident.

Audio only (AO): "Last Sunday my dog got hit by a truck." You say:....(please write your oral response.)

All the production task questionnaires were collected after 40 minutes of starting of the task. Some students have ambiguity to some scenarios, a considerable help was provided to understand the scenario without interfering the expected result or students responses.

\section{RESULTS}

The written production task produced 456 responses from 24 students from translation and interpretation department in a private university. Each student's written production task consists of 19 scenarios, which include variety of conventional expressions of speech acts such as expression of gratitude, apologies, thanking, acceptance of offers, declining offers, receiving and declining invitation etc.

After transcription, all collected data were identified in the production database; all the responses were coded for the second time to clarify the frequency of appearance of conventional expressions in situational dialogue. For example, for scenario No.15, this scenario requires students to write their answers about introduction of a new friend, 19 students replies to the scenario as "nice to meet you $(n=19)$ ", and 3 students answer the scenario as "glad to meet you $(n=3)$ ". Aforementioned examples are also the case for other 18 scenarios; some conventional expressions demonstrate variability in terms of what is recorded in the formula literature (Nattinger \& Decarrio, 1992).

In the first scenario, students were asked to reply about an accident of dog hit by a car, $45.83 \%$ of students answers the as "I am sorry" with frequency of 11.10 students answers the scenario as "Oh, I hope" with $41.66 \%$ frequency, $4.1 \%$ out of all participants replies to this scenario by replying as "is he head" or "I am sad for you. "The results from this item is in accordance with original study of the finding done by Amanda Jo DeBoer (Deboer, 2015). In the original study, the replies from participants were "I am so sorry..." of the final accepted expressions, in our study, "I am so sorry" holds the highest frequency due to the fact that 11 participants replies it with the accepted final expression.

The following scenario is designed to elicit participants' reply towards accepting the offer, 16 students reply it with 
$\underline{\text { Table 1. Production task responses on conventional expressions }}$

\begin{tabular}{|c|c|c|c|c|}
\hline ID & Scenario & $\begin{array}{l}\text { Expression produced by non-native } \\
\text { speaker students }\end{array}$ & Frequency $(\%)$ & Final accepted expression \\
\hline R1 & Dog hit by a car & $\begin{array}{l}\text { I am so sorry }(n=11) \\
\text { Oh, I hope...( } n=10) \\
\text { I am sad for you }(1)\end{array}$ & $\begin{array}{c}45.85 \\
41.66 \\
4.1\end{array}$ & I am so sorry. $(\mathrm{n}=11)$ \\
\hline R2 & Pick a book for someone & $\begin{array}{l}\text { Thank you }(n=16) \\
\text { I am really happy }(n=3) \\
\text { That is nice }(n=2) \\
\text { Can you do this for me }(n=1) \\
\text { I would like to make it }(n=1)\end{array}$ & $\begin{array}{c}66.67 \\
12.5 \\
8.3 \\
4.1 \\
4.1\end{array}$ & Thank you $(n=16)$ \\
\hline R3 & Thanking for coming & $\begin{array}{l}\text { You are welcome }(n=8) \\
\text { Thanks for... }(n=5) \\
\text { It was good }(n=4) \\
\text { I am glad, I will come }(n=1) \\
\text { Left blank }(n=5)\end{array}$ & $\begin{array}{c}33.3 \\
20.8 \\
16.6 \\
4.1 \\
20.80\end{array}$ & No predominant phrases \\
\hline R4 & Help someone & $\begin{array}{l}\text { Yes, please }(n=9) \\
\text { I am looking for }(n=8) \\
\text { Thank you }(n=3) \\
\text { It would be good ( } n=3) \\
\text { No, I can find it by myself }(n=1)\end{array}$ & $\begin{array}{c}37.5 \\
33.33 \\
12.5 \\
12.5 \\
4.1\end{array}$ & $\begin{array}{l}\text { Yes, please, I am looking } \\
\text { for }(n=17)\end{array}$ \\
\hline R5 & Hold a line for someone & $\begin{array}{l}\text { Yes, of course }(n=19) \\
\text { Sorry, I cannot }(\text { could not })(n=3) \\
\text { No, I cannot }(n=2)\end{array}$ & $\begin{array}{l}79.16 \\
12.5 \\
8.33\end{array}$ & Yes, of course $(n=19)$ \\
\hline R6 & Have a nice day & $\begin{array}{l}\text { Thank you }(n=14) \\
\text { Have a nice day }(n=4) \\
\text { You too }(n=5) \\
\text { Left blank }(n=1)\end{array}$ & $\begin{array}{c}58.33 \\
16.6 \\
20.83 \\
4.1\end{array}$ & Thank you $(n=14)$ \\
\hline R7 & Late 5 minutes for meeting & $\begin{array}{l}\text { I am sorry }(n=23) \\
\text { I apologize }(n=1)\end{array}$ & $\begin{array}{c}95.83 \\
4.1\end{array}$ & I am sorry...(n=23) \\
\hline R8 & Bring someone's book & $\begin{array}{l}\text { I am sorry } \ldots(n=23) \\
\text { Yes, I can bring it }(n=1)\end{array}$ & $\begin{array}{c}95.83 \\
4.1\end{array}$ & I am sorry. $(n=23)$ \\
\hline R9 & Thanks for the ride & $\begin{array}{l}\text { You are welcome }(n=12) \\
\text { No problem }(n=5) \\
\text { Never mind }(n=3) \\
\text { Thank you }(n=3) \\
\text { Left blank }(n=1)\end{array}$ & $\begin{array}{c}50 \\
20.83 \\
12.5 \\
12.5 \\
4.1\end{array}$ & You are welcome. $(\mathrm{n}=12)$ \\
\hline R10 & Come on Friday party & $\begin{array}{l}\text { No, I am sorry }(n=15) \\
\text { Yes, (thank you, of course) }(n=8) \\
\text { I need to check my to-do-list }(n=1)\end{array}$ & $\begin{array}{c}62.5 \\
33.33 \\
4.1\end{array}$ & No, I am sorry $(n=15)$ \\
\hline R11 & Studying in a library & $\begin{array}{l}\text { Yes, it is ok }(n=22) \\
\text { Left blank }(n=2)\end{array}$ & $\begin{array}{c}91.67 \\
8.34\end{array}$ & Yes, it is ok $(n=22)$ \\
\hline R12 & Do not need help & $\begin{array}{l}\text { Yes, thank you }(n=4) \\
\text { No, thank you }(n=20)\end{array}$ & $\begin{array}{l}16.67 \\
83.33\end{array}$ & No, thank you $(\mathrm{n}=20)$ \\
\hline R13 & Talk to your teacher & $\begin{array}{l}\text { Do you have time.? }(\mathrm{n}=10) \\
\text { I want (need) to talk to... }(\mathrm{n}=11) \\
\text { Thanks }(\mathrm{n}=3)\end{array}$ & $\begin{array}{c}41.67 \\
45.84 \\
12.5\end{array}$ & I need to talk to you $(n=11)$ \\
\hline R14 & Replying to the invitation & $\begin{array}{l}\text { Yes, I will join. }(\mathrm{n}=19) \\
\text { Sure, I could come. }(\mathrm{n}=4) \\
\text { Left blank }(\mathrm{n}=1)\end{array}$ & $\begin{array}{c}79.17 \\
16.67 \\
4.1\end{array}$ & Yes, I will join. $(n=19)$ \\
\hline R15 & Introducing someone & $\begin{array}{l}\text { Nice to meet you }(n=19) \\
\text { Glad to meet you }(n=3) \\
\text { Hello, I am pleased to meet you }(n=1) \\
\text { Hello, how are you? }(n=1)\end{array}$ & $\begin{array}{c}79.16 \\
12.5 \\
4.1 \\
4.1\end{array}$ & Nice to meet you $(n=19)$ \\
\hline R16 & Participating the funeral & $\begin{array}{l}\text { I am sorry }(n=21) \\
\text { God rest his soul }(n=2)\end{array}$ & $\begin{array}{l}87.5 \\
8.34\end{array}$ & I am sorry. $(\mathrm{n}=21)$ \\
\hline
\end{tabular}




\begin{tabular}{|c|c|c|c|c|}
\hline ID & Scenario & $\begin{array}{l}\text { Expression produced by non-native } \\
\text { speaker students }\end{array}$ & Frequency (\%) & Final accepted expression \\
\hline R17 & Make-up test & $\begin{array}{l}\text { Thank you. }(n=19) \\
\text { Sorry, it will not happen again }(n=4) \\
\text { Can you make a make-up test fort his } \\
\text { time }(n=1)\end{array}$ & $\begin{array}{c}79.16 \\
16.66 \\
4.1\end{array}$ & Thank you $(\mathrm{n}=19)$ \\
\hline R18 & Offering a ride & $\begin{array}{l}\text { Yes, thank you. }(\mathrm{n}=20) \\
\text { No, thanks }(\mathrm{n}=4)\end{array}$ & $\begin{array}{l}83.34 \\
16.67\end{array}$ & Yes, thank you. $(n=20)$ \\
\hline R19 & Need more food & $\begin{array}{l}\text { No, I am full }(\mathrm{n}=10) \\
\text { Thank you }(\mathrm{n}=2) \\
\text { No, thanks }(\mathrm{n}=12)\end{array}$ & $\begin{array}{c}41.67 \\
8.34 \\
50\end{array}$ & No, thanks. $(\mathrm{n}=12)$ \\
\hline
\end{tabular}

$\mathrm{R}=$ Responses, $\mathrm{n}=$ Numbers of frequency

"Thank you" with the frequency of $66.66 \%$. "I am really happy" yields $12.5 \%$ of frequency, "that is nice" is also seen with $8.3 \%$ of frequency, "can you do this for me" and "I would like to make it" shares the same percentage of $4.1 \%$. The accepted final answer in original study is "that would be great", but in this study "that would be nice" takes the frequency of $8.3 \%$.

Scenario No.3 is about deflecting thanks, from the students reply, it can be seen that participants did not understand the scenario, $20.8 \%$ of participants left the answers blank, 33.3\% of participants replies "you are welcome", $4.1 \%$ of participants wrote, "I have no time". However, in the original study, accepted final expression is "thanks for having me". It can be concluded that participants misunderstood or did not understand the given scenario, or it could be drawn to the conclusion that participants had no idea about what has to be replied to the scenario.

The next scenario is about accepting the request, It is found that $33.33 \%$ of participants reply it with "I am looking for...", which agrees with the original study in which "I am looking for" is seen with frequency of 12 . In our study, 8 participants answers it in the same way.

In the $5^{\text {th }}$ scenario, it is tested to reply someone's request, $79.16 \%$ of students answered as "yes, of course", 3 students answered "no, I cannot or I could not", $8.33 \%$ participants directly declined the request with the frequency of 2 . In the original study, it was concluded that as "sure, no problem" which was replied by 17 respondents. In the following scenario, expressing sorry is tested on students' ability to produce. In the original study, "you too" holds the highest frequency in which 20 participants replied as "you too", but in our investigation, "thank you" takes the highest proportion with the percentage of $58.33 \%$. 1 student did not reply the scenario, and 4 participants answered "have a nice day" instead of "you too".

In the scenario No.8, students are required to express the excuse for being late. In this scenario, 23 students out of 24 replied as "I am sorry" while one participant replied, "I apologize for" with the frequency of $4.1 \%$. The results from this research is similar with the previous study in which 14 participants replied, as "I am sorry". In the next scenario, according to the original study, "no problem" holds the highest percentage of frequency while in our examination, it is found that "you are welcome" shares the highest frequency of percentage. "No problem" only holds $20.83 \%$ of total responses.

In the scenario No. 11, it is found that most of the respondents replied as "yes, it is ok" with the $91.67 \%$ of frequency while in the original study "that works for me" takes the most responses form participants. In this scenario, 2 participants left the answers blank. In the following scenario, it was designed to elicit students replies on declining an offer or assistance, $83.33 \%$ students replies "no, thank you" whereas in the original study, "I am just looking" had the highest frequency with 13 respondents. In the $14^{\text {th }}$ scenario, accepting an invitation is tested, 19 students replied, "yes, I will join" while expecting answer is "I'd love to".

The results from $15^{\text {th }}$ scenario significantly matches the original study due to the fact that $79.16 \%$ of participants replied "nice to meet you" with the replies of 19 participants in our study, in the original research "nice to meet you" is answered by 18 participants. It can be reached a conclusion that students from translation and interpretation department quite familiar with the usage of this conventional expression. The next scenario was asked to express sorry to the funeral, "I am sorry" is produced by students with highest percentage of $87.5 \% .8 .34 \%$ of participants used "god rest his soul" which indicates that they have a high level of using conventional expressions in this situation.

Results from the last three scenario is also in accordance with the original research's findings. In scenario No. 17, students were asked to write their oral responses on expressing gratitude towards teacher's make-up test, $79.16 \%$ participants replied "thank you" with frequency of 19 , In the original study also calculated 12 participants with the same responses to the same scenario. The last scenario is on refusing an offer on food, 50\% participants replied as "No, thanks" with the frequency of $12,41.67 \%$ of participants answered as "No, I am full", with comparison to original study, quite similar result is found in the investigation of second language learners' production of conventional expressions.

\section{CONCLUSION}

This investigation was set out to elicit second language learners' production of conventional expressions in L2 pragmatics. There were 24 students from second grade from translation and interpretation department in a private univer- 
sity. From our research, it can be concluded that students are familiar with expressing themselves in various situation whereas they are unaware or they have no idea to express themselves in some scenarios. It can be viewed plainly that students did not understand especially scenario No. 3. The example is given below;

Scenario No:3, "There is a reception on campus. The organizer invited you and a few other students as well. It is getting late, and you decide to leave. You go over to the organizer."

(AO): "Thanks for coming."

In this scenario, the expected answer is "Thanks for having me", but majority of students with the percentage of 33\% replied to this scenario as "you are welcome", it can also noticed that $4.1 \%$ students answered as "I have no time", with the aforementioned percentage of $4.1 \%$ participants replied as "I am glad, I will come". It can also be viewed that $20.8 \%$ of students answered "thanks for inviting me" which approximately related to the expected answer. Answers left blank accounted for $20.8 \%$ of total research. The same situation also were seen in the scenario No.6 with 1 blank, No.9 with 1 blank, No.11 with 2 blank and No. 14 with 1 blank respectively.

With the regard to the expected answers and given replies, it can be clearly illustrated from our research that the very similar results have been achieved in comparison with the original study. For instance for scenario 1, in the original study, the match between expected answers and given replies was 17 , in our research the number of participants replied was 11 . For scenario no.2, original study outcome with 14 participants for expected answers, but in our study the number of participant is only 2. For scenario no.4' answers also matches with the expected replies with $33.33 \%$ of frequency.

Scenario no. 5 also had the similar results: in our study, 19 participants answered with the expected answers, and original study appeared with 17 participants who replied with the agreement of expected answers. In our research the answers given to scenario no.7 matched with the findings with the original study. In original study, 14 participants replied closely to the expected answers, and in our research, the number is 23 which is slightly higher than the percentage of original study. For scenario no. 15 had the highest match among other replies in our investigation, it can be seen that 18 people replied "nice to meet you", which is a expected answer, and in our study 19 students answered with the expected answers.

It can be also observed from our investigation that some participants replied to the scenarios with irrelevant answers such as in scenario No.3. Some participants answered, as "I have no time" while the scenario tested participants ability on producing conventional expressions. The result from this tells us 2 things: 1 . Students do not understand the given scenario. 2. Students have no idea about expressing themselves in this situation even they understand the scenario completely. Form these; we can conclude that pragmatic knowledge is very important in language education and teaching pragmatics when teaching should be emphasized to reiterate their speaking ability with the written or formulaic language.

From our research, it can be concluded that the most recognized and widely used conventional expressions are "thank you", "yes, of course", "I am sorry...", "nice to meet you". In addition, it can also concluded that the least or not widely used conventional expressions are "thanks for having me", "that would be great", "that works for me" in our investigation among non-native speakers.

Another interesting finding in our investigation is that most participants provided the reasons for each scenarios when replying to the scenario. For example, in scenario No.7, the scenario asked participants to reply to the scenario to express their sorry, lots of participants used "I am sorry..." as conventional expressions, at the same time, they provided the reason why they were late. It is not the case only for this scenario, for other scenario, participants also offered the reasons for expressing their conventional expressions.

Overall, it can be drawn to the conclusion that low production of some conventional expression in some scenarios can be attributed to a lack of access to the conventional expressions of learners. Investigation and the data from research illustrates that sociolinguistic knowledge has the relevant interaction with the knowledge of conventional expressions to determine which or what expressions to be used in these contexts. It can be said that low production among some learners reveals that interpretation of the context provided is the factor that learners' production of conventional expressions in some target language as appropriate for an alternative speech act.

\section{DISCUSSION}

In this part, the findings of this research is concluded and summary of our findings were discussed. From our research, we can come to the conclusion that conventional expressions in the view of development in second language pragmatics is regarded as pragma linguistic resource, and it should be emphasized in second language acquisition.

It can learned from House's study that instruction in L2 had the influence on learners' production of conventional expressions used in an appropriate context or situation, but interpretation is the case for native English speakers since non-native speakers have the difficulty or they found it ambiguous to interpret with accuracy (House, 1996).

Our findings also supported House's findings because interpretation the provided context is key to use the appropriate conventional expressions. In some scenarios of our investigation, it shows that some participants answered to the scenarios with the quite irrelevant replies, it is estimated that the participants had trouble interpreting the given context so that the inappropriate answers were given.

The findings from our research is quite similar with the previous studies. As an example for the finding in our study, some students had difficulties or they had trouble interpreting the context given, so it is concluded that pragmatic knowledge, not only conventional expressions, is beneficial for learners to improve their understanding and communication in every day speech acts. The similar results match the finding from Yusefi and Azizifar in which it suggested that it is important for learners to acquire pragmatics to develop their pragmatic competence (Yusefi, Gowhary, Azizifar, Esmaeli, 2015). 
From our literature review and introduction section, it could be observed that learning conventional expressions is responsive to instructions and it contained by the transparency of expressions and learners' level of linguistic improvements (Bardovi-Harling, Vellenga, 2012). The similar findings concluded our research that linguistic improvement is responsive to instructions and it is the transparency of linguistic knowledge of learners.

It concluded in our research that it is hard for second language learners to interpret the context provided, so that many answers to the scenarios were irrelevant to the scenario. It can be said that cultural background and contextual factors were involved when replying to these scenarios. This conclusion is also in agreement with the study performed by Uso-Juan et al. In their study, they also demonstrated that many foreign language learner finds pragmatic expressions, such as conventional expressions, difficult since contextual factors and cultural background involved in it. The aforementioned study suggested that foreign language learners are limited to make themselves clear when they express themselves in actual context (Uso-Juan, Martinez-Flor, 2015).

For all mentioned above, it can be concluded that developing students' linguistic knowledge is beneficial for second language learners. It can be claimed that importance of conventional expressions benefit to learners who use them (Coulmas, 1981, House, 1996). Another study carried out by Nurdan Gürbüz in 2017 reveals that conventional expressions or formulaic language in language learning is crucial to improve students' fluency in speaking. It is suggested that teachers play more important role in developing paralinguistic skills, so teachers are expected to, needless to say, motive or design speaking lessons and not to impair learners confidence by paying attention to the language mistakes learners make during the process of language learning and teaching (Gürbüz, 2017).

Concisely, language practitioners should remember that only teaching language skills such as listening, reading, writing and speaking are not enough, but also teaching pragmatic knowledge to boost their competence in all area of language learning has the equal importance in developing learner's sociolinguistic competence. This conclusion resulted from the findings that even students are upper or advanced language speakers, but learners are limited in expressing themselves in various pragmatic contexts. These findings suggest the importance of pragmatic competence and sociolinguistic competence of learners in language teaching and language learning process.

\section{ACKNOWLEDGEMENT}

I would like to thank my supervisor Assistant Prof. Dr. Çiğgem Karatepe, Uludağ University, Bursa, Turkey.

\section{REFERENCES}

Amanda, E. (2014). Conventional Expressions. Investigating Pragmatics and Processing. Studies in Second Language Acquisition, 36, 69-99.

Bardovi-Harlig, K. Bastos, M.T. et al. (2015). The use of conventional expressions and utterance length in L2 pragmatics. Pragmatics and Language Learning, 12.

Bardovi-Harlig, K. (2008). Recognition and production of formulas in L2 pragmatics. In Z.-H.Han (Ed.), Understanding second language process. 205-222. Clevedon, UK: Multilingual Matters.

DeBoer, Â.J.O. (2015). "Second Language Learners' Recognition and Production of Conventional Expressions: The Role of Proficiency, Length of Stay, and Intensity of Interaction". Culminating Projects in English.

Esther, U., Alicia, M. (2015). Assessing EFL learners' performance of the conventional expressions of complaining and apologising. Social and Behavioral Sciences, 173, $53-60$.

Gürbüz. N. (2017). Understanding Fluency and Disfluency in Non-native Speakers' Conversational English. Educational Science: Theory and Practice, 17, 1853-1874

Kathleen Bardovi-Harlig. (2012). Formulas, Routines, and Conventional Expressions in Pragmatics Research. Annual Review of Applied Linguistics, 32, 206-227.

Kathleen, B.H., \& Heidi, Velle, E. (2012). The effect of instruction on conventional expressions in L2 pragmatics. System, 40, 77-89.

Kathleen, B.H. (2009). Conventional Expressions as a Pragmalinguistic Resource: Recognition and Production of Conventional Expressions in L2 Pragmatics. Language Learning Research Club, University of Michigan, pp. 755-795.

Nattinger, J.R. \& Decarrico, J.S. (1992). Lexical Phrases and Language Teaching. Oxford: Oxford University Press.

Naoko, T. (2013). Production of routines in L2 English: Effect of proficiency and study-abroad experience. System $41,109-121$.

Roever. C. (2005). Testing ESL Pragmatics: Development and Validation of a Web-based Assessment Battery. Berlin: Peter Lang.

Yusefi et al. (2015). A pragmatic analysis of thanking strategies among Kurdish speakers of Ilam based on gender and age. Social and Behavioral Sciences. 199, 211-217. 